\title{
錨鎖に於ける懸垂曲線に就いての一考察
}

\section{A Study of Catenaries on Anchor Cables}

\section{川島利兵 衛…北大水産)}

\begin{abstract}
From the point of view of Mechanical Statis, when a ship is mooring with anchor and cables in water, the cable makes catenaries.

The equation of catnaries is given : as following

$$
z=\frac{T_{0}}{2 \sigma g}\left(e^{\frac{\sigma g}{T 0} x}+e^{-\frac{\sigma g}{T 0} x}\right)
$$

$\sigma g$ : Unit weight of cables $\mathrm{gr} / \mathrm{c} . \mathrm{m}$.

$T_{0}$ : Horizontal force on cable

Hence, the investigations were undertaken to find out the relation between horizontal force on cable to catenaries by the experimentary methods.

From above mentioned relation (the results of experiment), this paper described about the relation between holding fower of anchor and cables to the force worked on ship about the cable run out.
\end{abstract}

\section{1. 序}

\section{論}

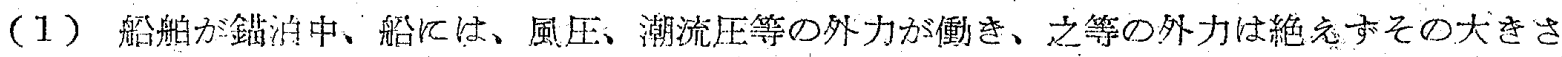
方向が変化する虑に、船注一定位置に静止するととなく、前後方向に或仕振狆迴り運動をする。

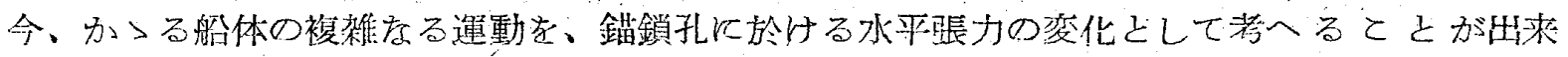

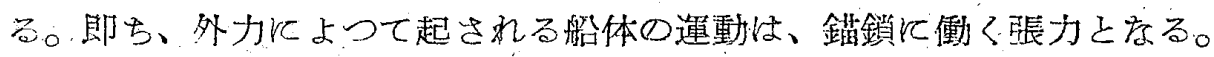

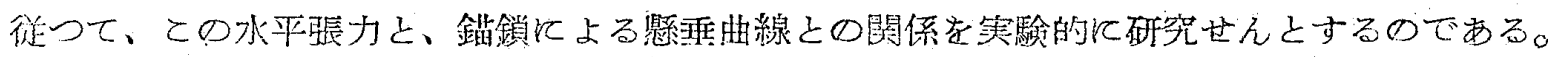

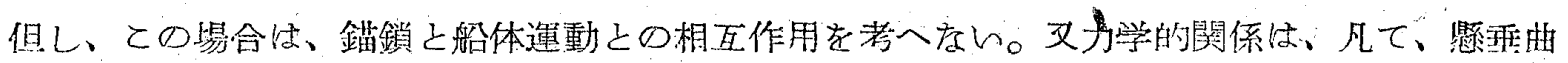
線を含さ平面に就んてのみ考へ、即ち、静的の場合飞就んて研究する。

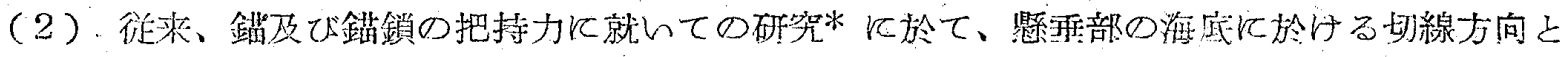
海底面之の存す觕老二 $\phi$ とする上

$$
\begin{aligned}
& \text { (i) } \phi \neq 0 \text { をる昜合 } \\
& \text { (ii) } \phi=0 \text { 表无昜合 }
\end{aligned}
$$

そ就々て論ぜられてるる。

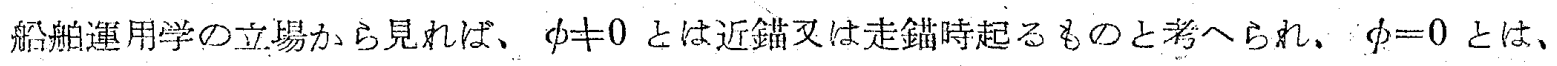

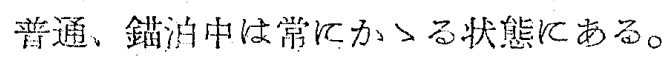

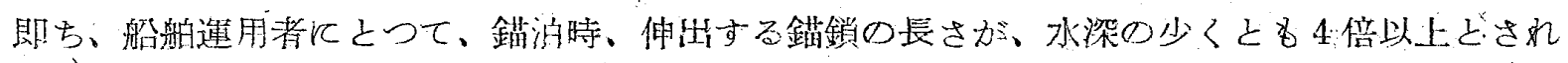

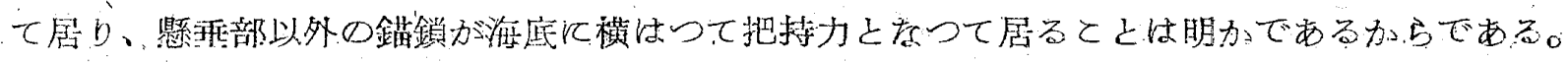

(3) 面て、怔垂曲線は、㳄の方程式で年へられる。 


$$
z=\frac{T_{0}}{2 \sigma g}\left(e^{\frac{\sigma g}{T 0} x}+e^{-\frac{\sigma g}{T 0} x}\right)
$$

$\sigma g$ ：単位長さに於ける鎑鎖の重さ。

$T_{0}$ ：錨鎖に㗢く水平涱力。

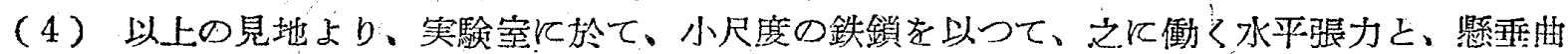
線との関係安穾験的飞研究する。

との関係とは、水平張力と、懸垂曲線の形状の変化であり、実験に於ては、水平張力と同時に

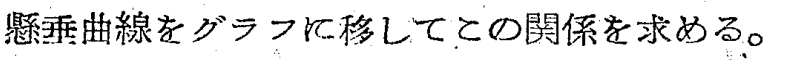

（5）之の結果上り定性的に、実際船舶飞於ける錨泊中の錨及び錨鎖の把駐力上、外力（即ち 水平脹力）亡の関䋆を、伸出されたる錯鎖に就んて考察する。

\section{2. 実 験}

䨋験に使用しを鎖

径 6 籷、全長 293粴、単位重量 $9 \cdot 74$ 正

(1) 実駰装 置

实験装置は、曲線測定と、辳力測定の 2 つ部分上り成る。

i）曲線測定装置、高さ150 筫、圆

徚、長さ300彩厘の木製の桃 亿縦横 5 糎間湢のグラフ眼 をアミラン、タングス糸で 作り、之を頱の懸吊部の雨 側飞平行以配置与る。

ii）嬖力測是装置、曲楾測 定装置上同高の㭠上飞、水 平方向飞移動出来る様飞、 張力測定杆を装置し、その 一端と、スプリング、バラ ンス (20kg) 孝配置し張力

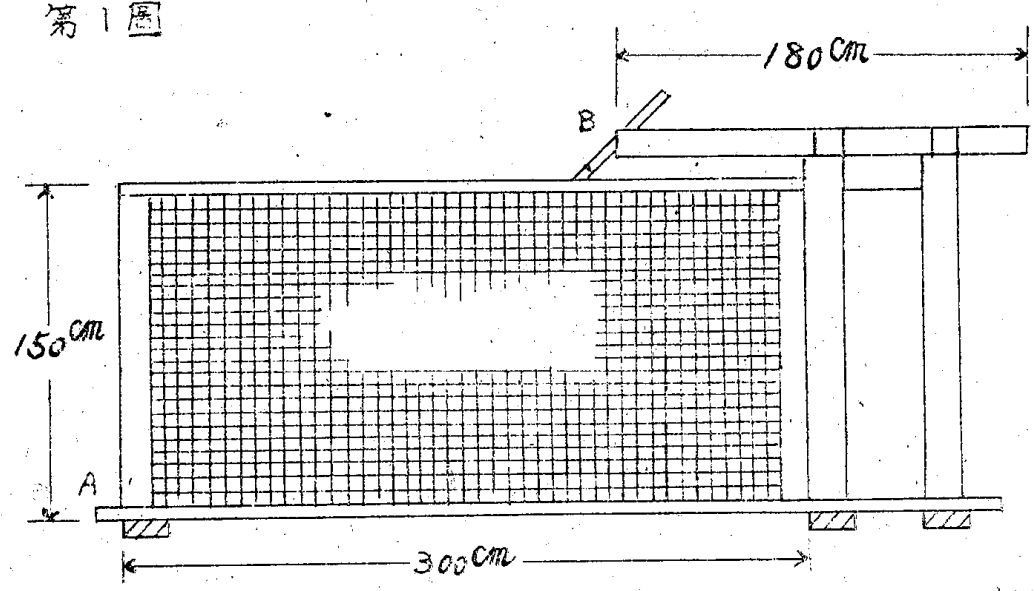

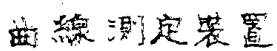

張的测定琵置

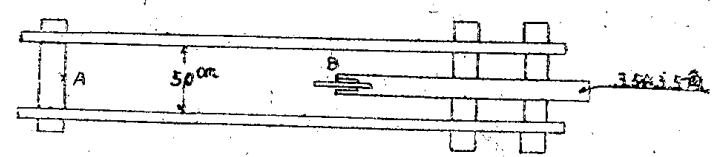

\section{(2) 実 験 方，法}

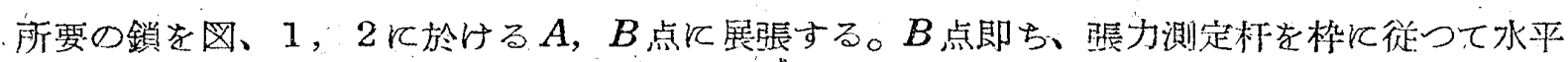

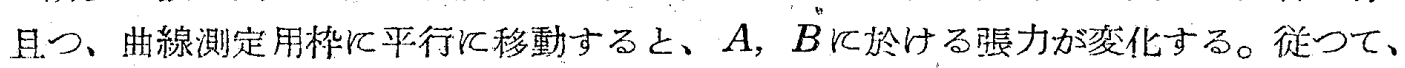

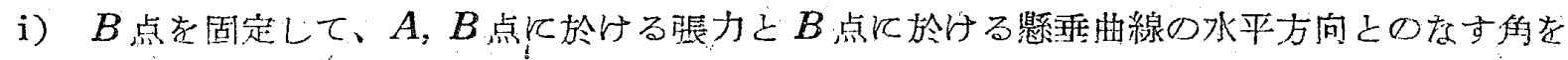
測定主石。

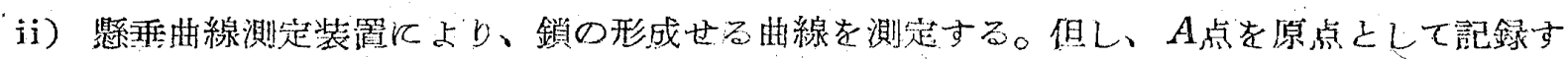
る。

(3) 实 驗 結 黑

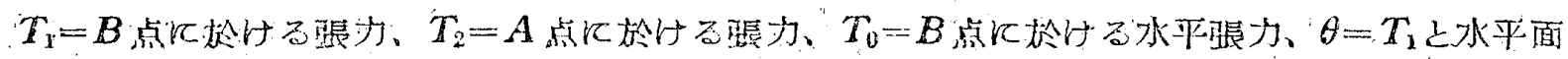

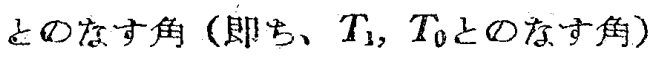


i）張力の測定結果

第 1 泰

\begin{tabular}{|c|cc|c|c|c|}
\hline 实驗番号 & $T_{1}(\mathrm{~kg})$ & $T_{2}(\mathrm{~kg})$ & $T_{3}(\mathrm{~kg})$ & $\theta$ (deg) \\
\hline$[1]$ & 3.5 & 2.0 & 2.06 & 53.8 \\
{$[2]$} & 3.9 & 2.3 & 2.45 & 51.0 \\
{$[3]$} & 4.5 & 3.0 & 3.07 & 47.0 \\
{$[4]$} & 5.6 & 4.0 & 4.06 & 43.5 \\
{$[5]$} & 7.7 & 6.2 & 6.13 & 37.2 \\
\hline
\end{tabular}

ii）曲線の測定結果

$A$ 点を原点として、測 定結果第3図任示吉。

但し、図中[1][2] [3][4][5]红实験番号安 示し、算 1 表住対応する。

(4) 理 論 式

(3) 項飞於て得られ学 る実験結果を(1)*式より 計算すると、次の諸式安得 万。

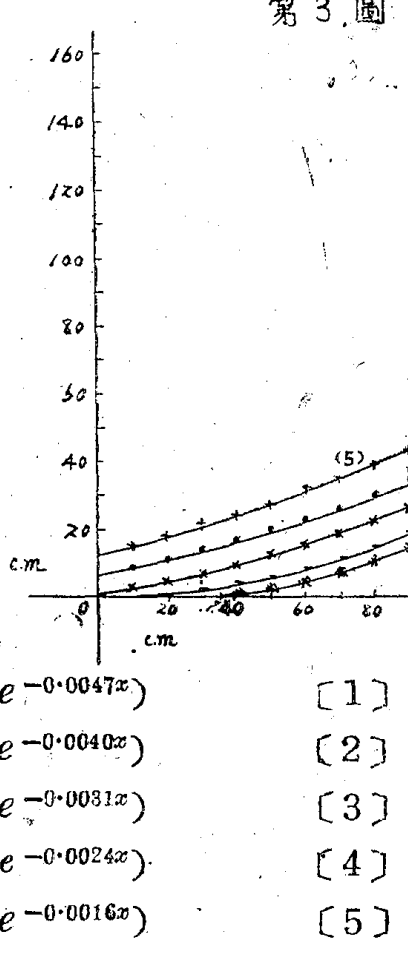

$$
\begin{array}{ll}
z=105.9\left(e^{0.0047 x}+e^{-0.0047 x}\right) & {[1]} \\
z=126.1\left(e^{0.0040} x+e^{-0.0040 x}\right) & {[2]} \\
z=157.7\left(e^{0.0031 x}+e^{-0.0031 x}\right) & {[3]} \\
z=208.7\left(e^{0.0024 x}+e^{-0.0024 x}\right) & {[4]} \\
z=315.2\left(e^{0.0016 x}+e^{-0.0016 x}\right) & {[5]}
\end{array}
$$

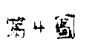

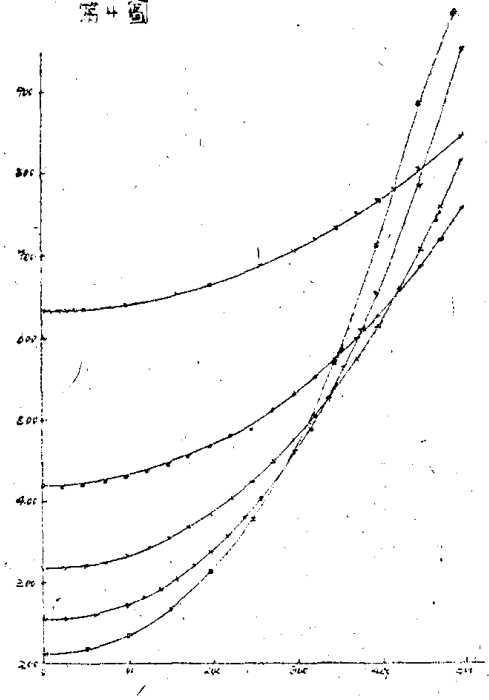

(5) 実験結果火就的ての考察

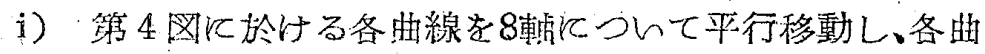

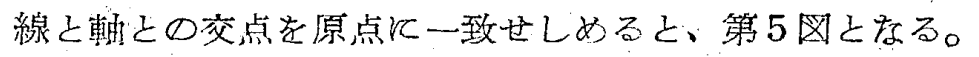

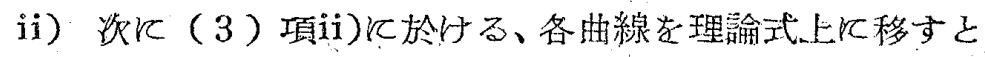
即占之第 5 図上飞求为る。

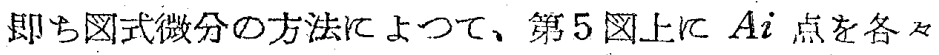
定め、之上り寒験值を記入すると、第6，7图を得る。

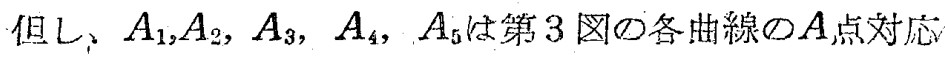
する。

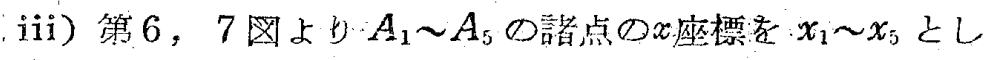

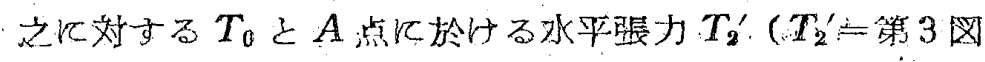

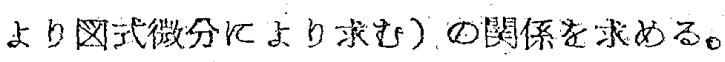


第6 図
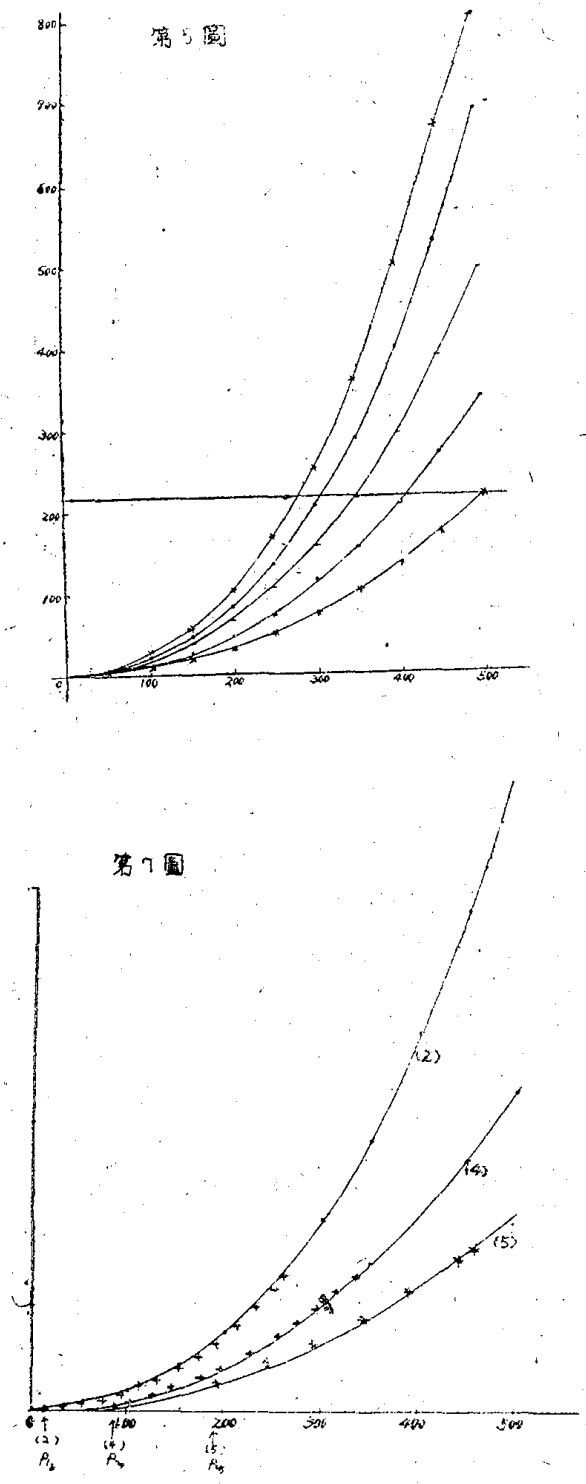

第 2 表

\begin{tabular}{|r|r|r|r|}
\hline & $T_{0}(\mathrm{~kg})$ & $T_{2}(\mathrm{~kg})$ & \multicolumn{1}{c|}{$x$} \\
\hline$[1]$ & 2.06 & 2.0 & -7.6 \\
{$[2]$} & 2.45 & 2.3 & 13.0 \\
{$[3]$} & 3.07 & 2.9 & 44.6 \\
{$[4]$} & 4.06 & 4.0 & 98.0 \\
{$[5]$} & 6.13 & 6.0 & 191.3 \\
\hline
\end{tabular}

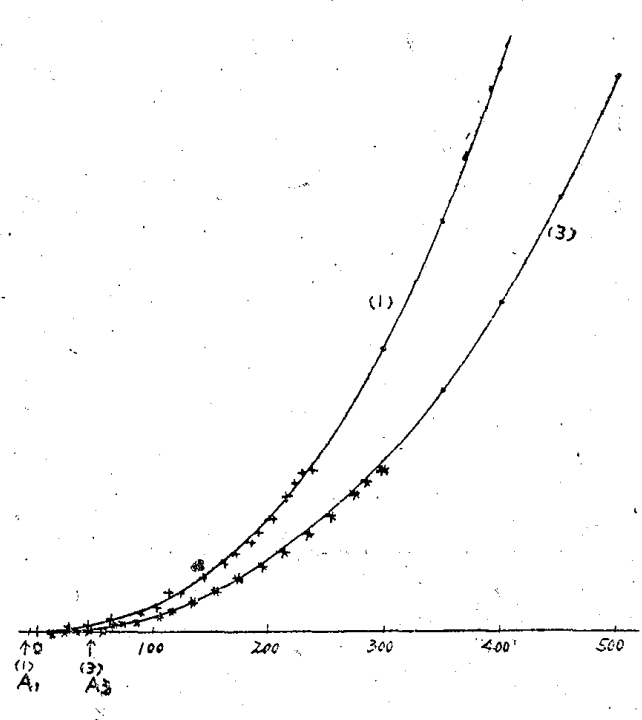

算 8 签

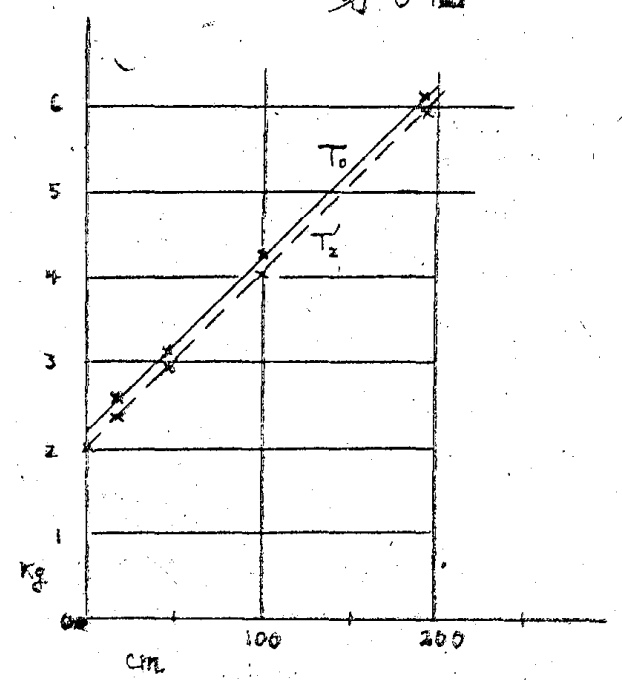

第.9.7.

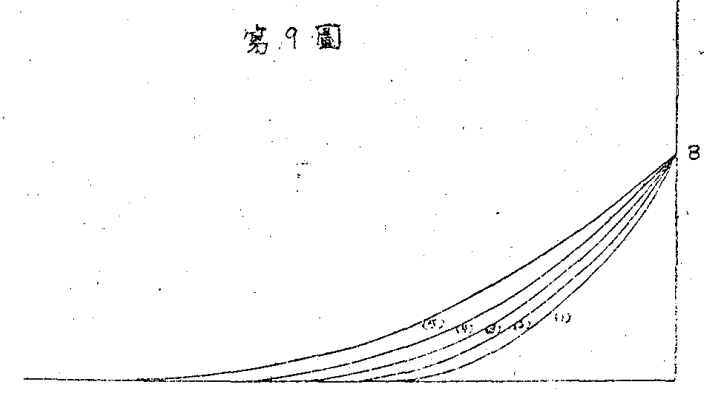

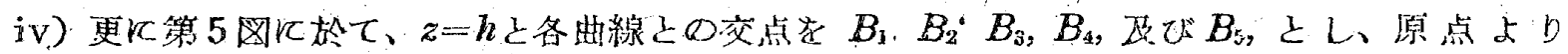

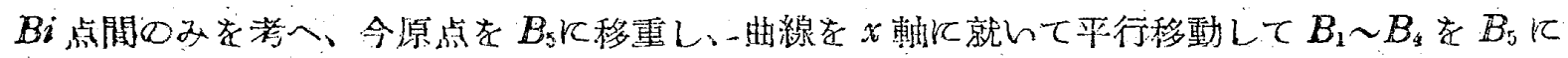

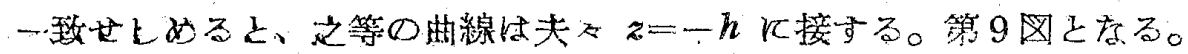




\section{3. 茬察}

以上の実驗結果に上りて明か存る如く、之より定性的飞次の諸項が導を出し得る。

(1) 序諭(2) 飞於て、述べを（i） $\phi \neq 0$ 及び（ii） $\phi=0$ とは、次の如く考へ得る。

即ら。之妾数学的飞考人机快、水平脹力の 桨化は、座標変換を伴ひその.形状を変化す る。

（2）錨及び錨鎖の把駐力己、外力（即与

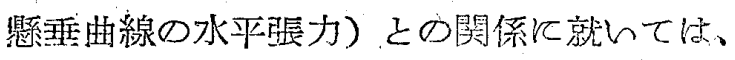
次のく如である。

$p$ : 錯及び䤮鎖の把眭力。

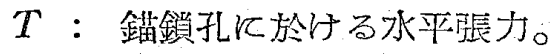
但し、之释舶飞㗢く外力口水平分力 そ等しんものとする。

$$
\begin{aligned}
& p=\phi(m, N, l) \\
& T=\varphi\left(h, N, l^{\prime}\right)
\end{aligned}
$$

但し、

$m=$ 底筫（游底）飞上り定李方係数

$N=$ 艤装数炕上b定皇。

\section{$l l^{\prime}=$ 錨鎖長}

$h=$ 水 樑

丈。 $l \cdot l^{\prime}$ 㤌共に $h$ 亿より垁委る長さ、 で表ぱされる。

而して、 $\phi, \phi$ 法次の形式で与へられる。

$$
\begin{aligned}
& \phi=A x+B \\
& \phi=a x^{2}+b x+C
\end{aligned}
$$
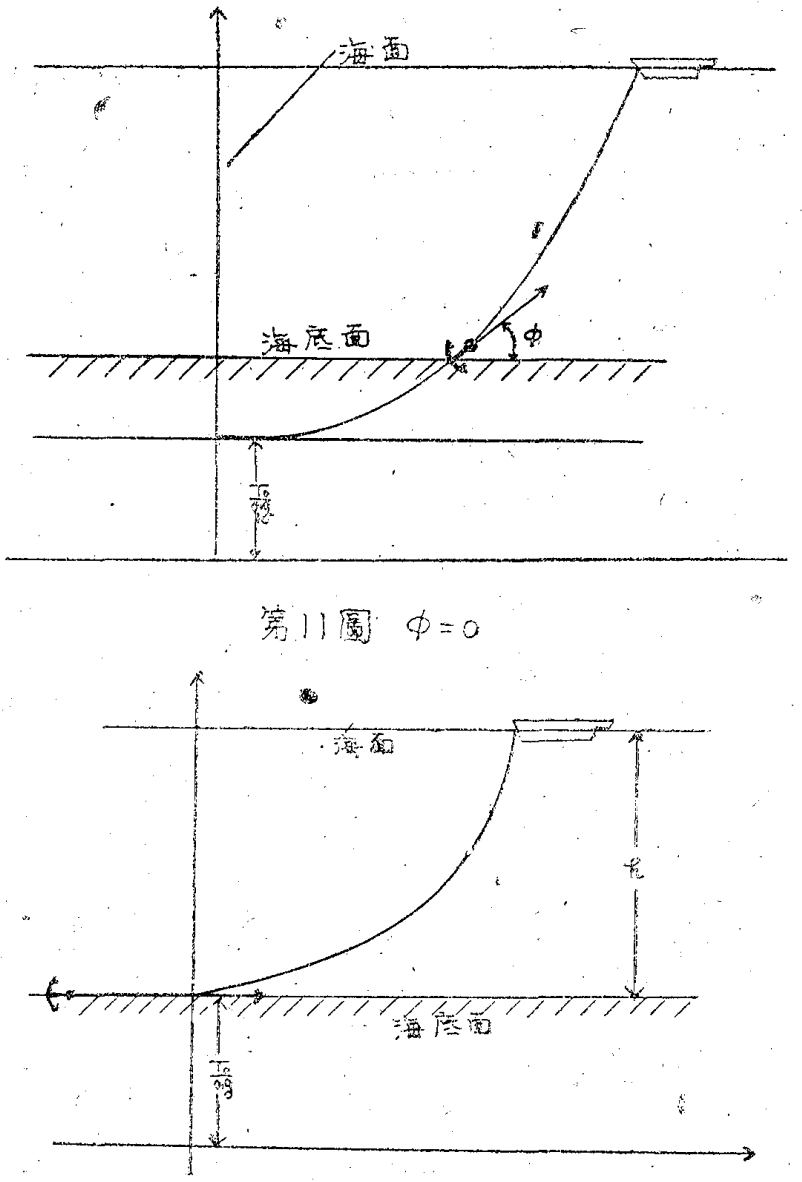

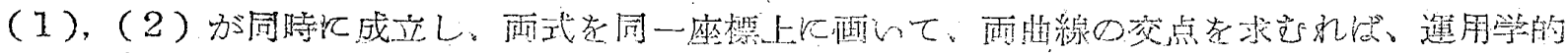

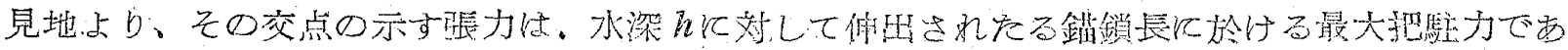
る。

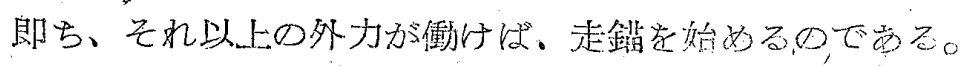

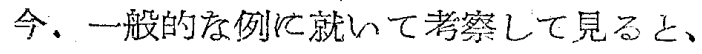

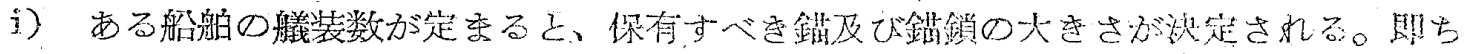

い二ある船の鍇の雵さ

$g W_{2}=$ 錨鎖の筫位長さの重さ

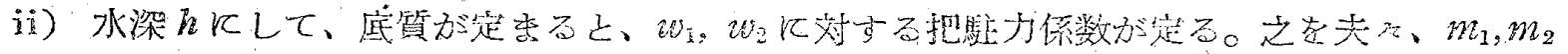

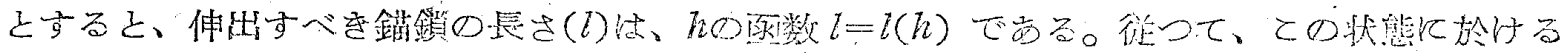
鍇及び錨鎖の把駐力P注、

$$
P=m_{1} w_{1}+m_{2} w_{2} \downarrow
$$

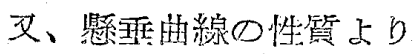




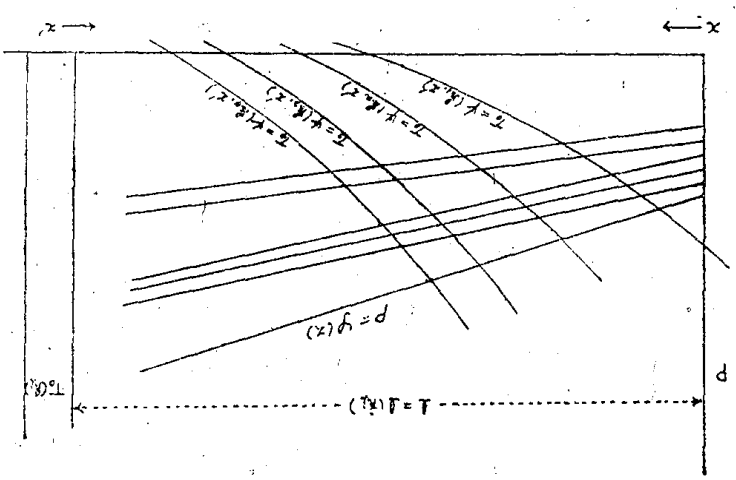

$T=\frac{w_{2}}{2}\left\{\left(\frac{l^{\prime}}{h}\right)^{2}-1\right\}$

$T=$ 錨鎖孔々於ける水平張力

$l^{\prime}=$ 懸重部の長さ、

iii）今、水深飞 $h$ 就んて、 $h_{1}, h_{\imath}, h_{3} \cdots$ として、 （5），(6）をグラフイして表ぜば、上述の性質 示す。第12园

\section{参考 文 献}

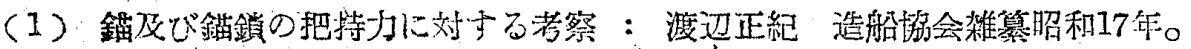

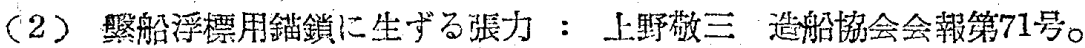

(3) 物理数学第一巻：小平吉男 